\title{
The Danish Lung Cancer Registry
}

This article was published in the following Dove Press journal:

Clinical Epidemiology

25 October 2016

Number of times this article has been viewed

\author{
Erik Jakobsen ${ }^{1,2}$ \\ Torben Riis Rasmussen ${ }^{3}$ \\ 'Department of Thoracic Surgery, \\ Odense University Hospital, ${ }^{2}$ Odense \\ Patient data Exploratory Network \\ (OPEN), Institute of Clinical Research, \\ University of Southern Denmark, \\ Odense, ${ }^{3}$ Department of Respiratory \\ Diseases and Allergy, Aarhus \\ University Hospital, Aarhus, Denmark
}

Correspondence: Erik Jakobsen Department of Thoracic Surgery, Odense University Hospital, Sdr. Boulevard 29, DK-5000 Odense, Denmark $\mathrm{Tel}+452149$ I I39

Email erik.jakobsen@rsyd.dk
Aim of database: The Danish Lung Cancer Registry (DLCR) was established by the Danish Lung Cancer Group. The primary and first goal of the DLCR was to improve survival and the overall clinical management of Danish lung cancer patients.

Study population: All Danish primary lung cancer patients since 2000 are included into the registry and the database today contains information on more than 50,000 cases of lung cancer.

Main variables: The database contains information on patient characteristics such as age, sex, diagnostic procedures, histology, tumor stage, lung function, performance, comorbidities, type of surgery, and/or oncological treatment and complications. Since November 2013, DLCR data on Patient -Reported Outcome Measures is also included.

Descriptive data: Results are primarily reported as quality indicators, which are published online monthly, and in an annual report where the results are commented for local, regional, and national audits. Indicator results are supported by descriptive reports with details on diagnostics and treatment.

Conclusion: DLCR has since its creation been used to improve the quality of treatment of lung cancer in Denmark and it is increasingly used as a source for research regarding lung cancer in Denmark and in comparisons with other countries.

Keywords: lung cancer, histology, tumor stage, lung function, performance, comorbidities, diagnostic procedures, type of surgery, oncological treatment, treatment complications

\section{Aim of database}

The Danish Lung Cancer Registry (DLCR) was established by the Danish Lung Cancer Group (DLCG). The primary goal of DLCG and later of the DLCR was to improve survival and the clinical management of Danish lung cancer patients. A secondary aim has been to produce a platform for lung cancer research. DLCG was established in 1991 and representatives from medical specialties working with lung cancer were invited to participate. Several published papers indicated that the survival of lung cancer patients in Denmark was inferior to international standards and that no improvement in the relative 5-year survival had been observed for several years. ${ }^{1-3}$ It was the general perception among experts that the only way to reduce the number of deaths from lung cancer was to intensify the public campaigns against smoking. ${ }^{4}$ In 1990, more than 90 departments took part in diagnostics and treatment of lung cancer in Denmark, and a survey performed by the DLCG demonstrated major variation in the clinical management. The DLCG therefore decided to create a set of national guidelines for the management of lung cancer in Denmark. The first edition was published in 1998 and the DLCG adopted a strategy to implement the guidelines and concurrently monitor the implementation by reporting to

Clinical Epidemiology 20I6:8 537-54I (Thematic series on clinical quality databases in Denmark) $\mathbf{5 3 7}$ (c) (1) (2) $\odot 2016$ Jakobsen and Rasmussen. This work is published and licensed by Dove Medical Press Limited. The full terms of this license are available at https://www.dovepress.

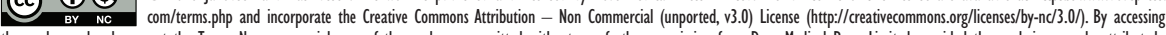
the work you herby accept the Tems. Non-commercial uses of the work are permitted without any further permission from Dove Medical Press Limited, provided the work is properly atributed. For permission for commercial use of this work, please see paragraphs 4.2 and 5 of our Terms (https://www.dovepress.com/terms.php).
Dovepress

http://dx.doi.org/10.2147/CLEP.S99458 
a new registry established by the DLCR. The first patient was included in DLCR on January 1, 2000.

\section{Study population}

All Danish lung cancer patients are included into the registry. With the currently used methods for retrieving information about Danish lung cancer cases, the inclusion of incident cases since 2003 is estimated to be above $95 \%$ and the database today contains data on more than 55,000 cases of lung cancer including cancer of the trachea. Between 2000 and 2002, clinicians identified and reported patients to DLCR, but since 2003, the lung cancer patients are identified in the Danish National Patient Registry (DNPR), ${ }^{5}$ where the first occurrence of the diagnostic codes DC34 and DC33 according to the International Classification of Diseases, 10th Revision (ICD-10) is identified. These patients and their activities (procedures and treatments) form a basic database with information derived from the DNPR and the Danish Pathology Register (DPR $)^{6}$ data alone. Subsequently, the basic database is used as a source for building the final qualified database (DLCR), which is on variable level validated and supplemented online by clinicians. All departments involved in the diagnosis and treatment of lung cancer in Denmark participate in DLCR and are responsible for the validation and supplementation of data. Since the participation is mandatory by law, data completeness is very high (more than 90\%). Data on comorbidity is obtained from the DNPR.

\section{Main variables}

The database today contains information on patient characteristics such as age, sex, diagnostic procedures, histology, tumor stage, lung function, performance, comorbidities, type of surgery, and/or oncological treatment and complications registered. Information on vital status for each patient is retrieved from the Danish Civil Registration System. ${ }^{7}$ Age at time of diagnosis and sex are inferred from the personal identification number (PIN), a unique system identifying age and sex of all Danish citizens. Since November 2013, DLCR also has Patient-Reported Outcome Measures (PROMs), the first year after treatment has finalized. PROMs are evidence of patient-experienced health status, and are be applied to evaluate the experiences and needs of the lung cancer patients. Monitoring symptoms, functional capacity, and quality of life have the potential to improve quality and the result of treatment effort. The European Organization for Research and Treatment of Cancer (EORTC) 30 and EORTC-LC13 are used as questionnaire. ${ }^{8,9}$
The recorded diagnostic procedures are the procedures performed in cases suspected of lung cancer to diagnose the disease and the type of lung cancer, and to conclude on treatment options based on these informations and the staging of the lung cancer, lung function, the performance of the patient, and relevant comorbidities. DLCR also provide data concerning delays in the diagnostic evaluation and treatment. For the classification of comorbidity, the Charlson's comorbidity index ${ }^{10}$ is used.

Details on surgical treatment are recorded including dates, type of surgery, and complications. Information on primary oncological treatment includes the amount and type of radiation therapy, and the type and duration of chemotherapy.

\section{Follow-up}

After the primary treatments are finalized, all patients are offered to enter a follow-up program consisting of clinical controls and computed tomography scans in fixed intervals. The contents of and time spacing between the follow-up visits are according to national guidelines on follow-up of lung cancer, and these procedures together with information on treatment of recurrence are registered in the DLCR. The patient's vital status is updated in the database once a month.

\section{Examples of research}

The first peer-reviewed articles based on the data in DLCR were published in 2009 and since an increasing number of papers have been published yearly. Publications based on the DLCR are yearly listed in the annual report. ${ }^{11}$

A number of papers have focused on documenting the effects of a national clinical database such as the DLCR. Thus, Jakobsen et $\mathrm{al}^{12}$ in 2013 published a work entitled "Nationwide quality improvement in lung cancer care: the Danish Lung Cancer Registry," in which they conclude "that a comprehensive national quality management system including national guidelines, a database with high data quality and completeness, frequent reports to the professionals and the public, audit and commitment from all stakeholders can contribute to improve practice and results and reduce regional differences." Table 1 shows the quality indicators used in DLCR in 2013. These indicators are continuously being evaluated and revised. Figure 1 is an example on how the indicators are reported in the annual reports. This indicator shows the degree of accordance between the clinical stage of the lung cancer and postoperative stage and is one of the most important quality indicators of the diagnostic set up. 
Table I The quality indicators used in DLCR in 2014

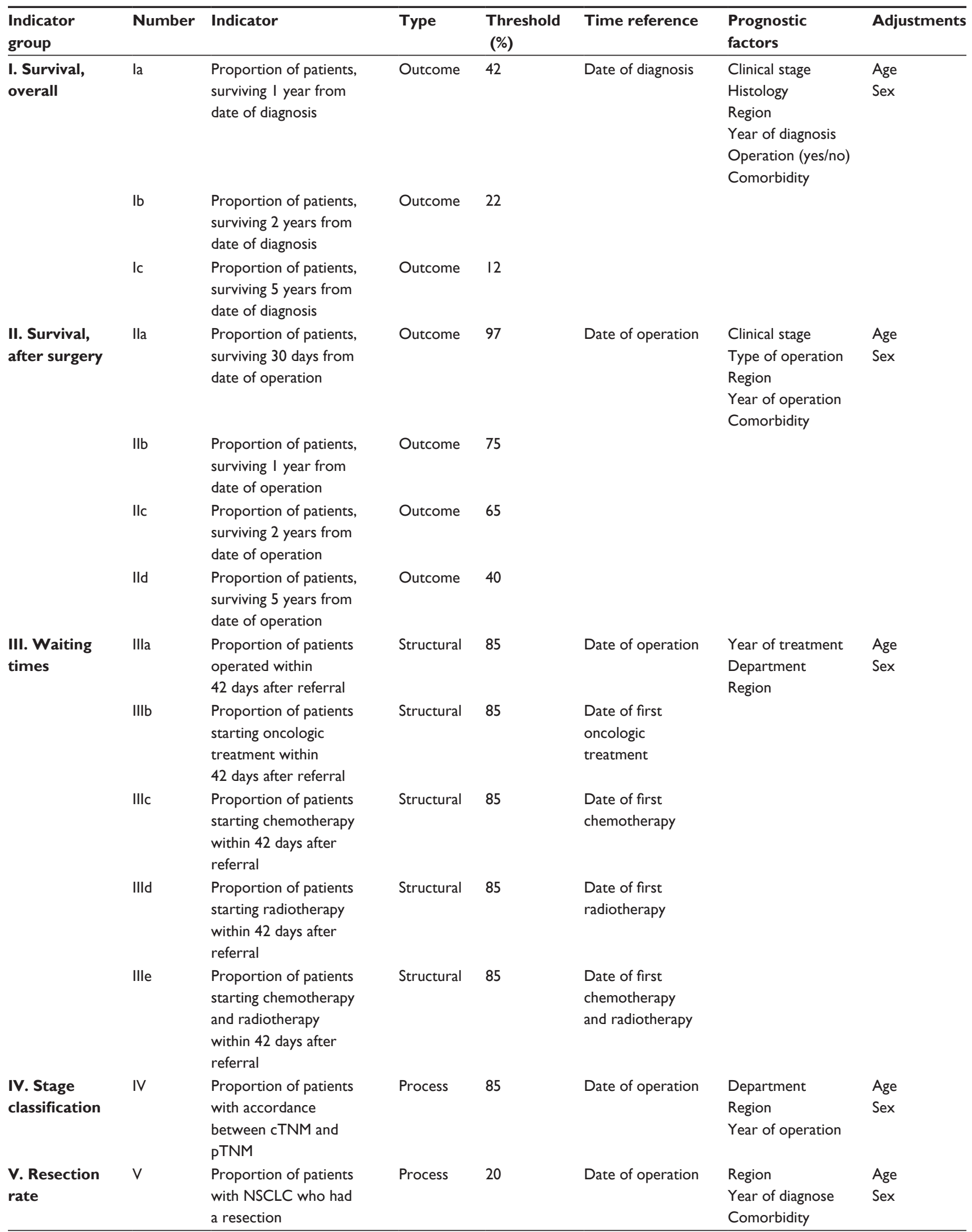

Abbreviations: DLCR, Danish Lung Cancer Registry; cTNM, clinical stage of the lung cancer; NSCLC, non-small-cell lung cancer; TNM, tumor node metastasis; PTNM, postoperative stage. 


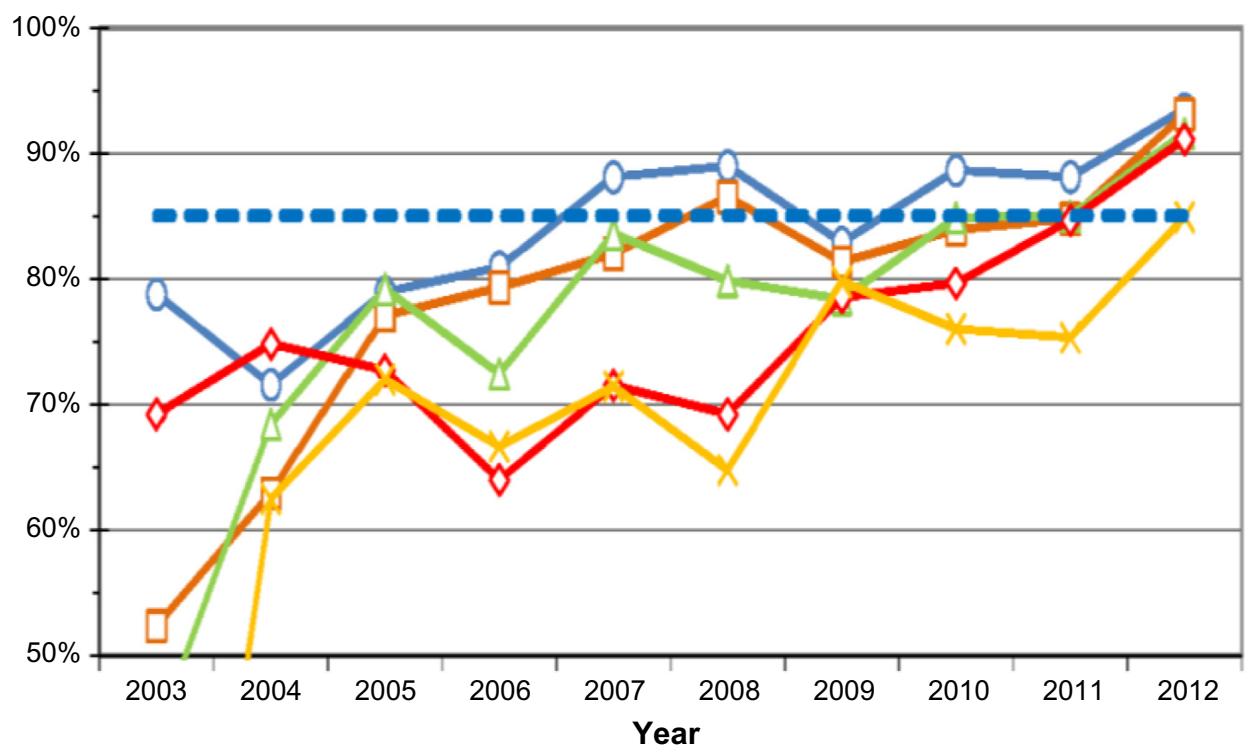

Figure I Time trends in the accordance between cTNM and PTNM across health care region.

Abbreviations: cTNM, clinical stage of the lung cancer; TNM, tumor node metastasis; PTNM, postoperative stage.

The higher accordance, the better quality of the diagnostic set up and the higher the probability of the patient receiving the optimal treatment. The indicator shows the different result in the five Danish regions.

The research based on the data in DLCR furthermore has focused on two main topics, comorbidity and inequality. In four consecutive articles, the importance of comorbidity in lung cancer treatment and survival has been evaluated. ${ }^{13-16}$ Socioeconomic position and different aspects of lung cancer have been explored in another series of papers with the overall conclusion that socioeconomic position is a major prognostic factor in lung cancer survival and treatment. ${ }^{17-19}$ These and other publications document the growing importance of national and international cooperation in lung cancer research.

\section{Administrative issues and funding}

DLCR is one of the national supported databases organized under the administration of the Joint Secretariat for the Danish Clinical Quality Improvement Program (Databasernes Fælles-sekretariat, Regionernes Kliniske Kvalitetsudviklings program, RKKP). Furthermore, the DLCG is a part of the Danish Multidisciplinary Cancer Groups (DMCG.dk), a national network of physicians and other health care professionals, scientists, and government officials committed to improving cancer care in Denmark. Funding is through the Danish Clinical Quality Improvement Program. Data in the clinical databases connected to RKKP including DLCR are on application to the organizations available for all Danish researchers.

\section{Conclusion}

DLCR contains information on every incident primary case of lung cancer in Denmark since 2003. The variables include patient age, sex, diagnostic procedures, histology, tumor stage, lung function, performance, comorbidities, type of surgery, and/or oncological treatment, complications registered, and the patient's vital status. Since November 2013, DLCR also have included PROMs the first year after treatment has been finalized. DLCR has, since its creation, been used to improve the quality of treatment of lung cancer in Denmark and it is increasingly used as a source for research regarding lung cancer in Denmark and in comparisons with other countries.

\section{Acknowledgments}

DLCR is managed in close collaboration with Competence Centre South for National Clinical Databases at Odense University Hospital. This article is part of the Thematic Series Clinical Databases in Denmark initiated by the Program for Clinical Research Infrastructure (PROCRIN).

\section{Disclosure}

The authors report no conflicts of interest in this work.

\section{References}

1. Tulinius H, Storm HH, Pukkala E, Andersen A, Ericsson J. Cancer in the Nordic countries, 1981-86. A joint publication of the five Nordic Cancer Registries. Acta Pathol Microbiol Immunol Scand. 1992;100(31): $1-94$.

2. Hansen J, Olsen JH. Survival of Danish cancer patients 1943-1987. Respiratory system. APMIS Suppl. 1993;33:77-98. 
3. Andersen KB. Lung cancer-better prognosis? Ugeskr Laeger. 1994;156(33):4719-4720.

4. Engeland A, Bjorge T, Haldorsen T, Tretli S. Prognosis of patients with lung cancer diagnosed in Norway, 1954-93. Cancer Causes Control. 1998;9:57-65.

5. Lynge E, Sandegaard JL, Rebolj M. The Danish national patient register. Scand J Public Health. 2011;39(7 Suppl):30-33.

6. Bjerregaard B, Larsen OB. The Danish pathology register. Scand J Public Health. 2011;39(7 Suppl):72-74.

7. Pedersen CB. The Danish civil registration system. Scand J Public Health. 2011;39(7 Suppl):22-25.

8. Aaronson NK, Ahmedzai S, Bergman B, et al. The European Organization for Research and Treatment of Cancer QLQ-C30: a quality-oflife instrument for use in international clinical trials in oncology. J Natl Cancer Inst. 1993;85(5):365-376.

9. Bergman B, Aaronson NK, Ahmedzai S, Kaasa S, Sullivan M. The EORTC QLQ-LC13: a modular supplement to the EORTC Core Quality of Life Questionnaire (QLQ-C30) for use in lung cancer clinical trials. EORTC Study Group on Quality of Life. Eur J Cancer. 1994;30A(5):635-642.

10. Charlson ME, Pompei P, Ales KL, MacKenzie CR. A new method of classifying prognostic comorbidity in longitudinal studies: development and validation. J Chronic Dis. 1987;40:373-383.

11. Årsrapport 2014 Dansk Lunge Cancer Register (Danish). Available from: http://lungecancer.dk/documents/ED76D14E-3915-4D9C9033-55D1B03402FB.pdf. Accessed January 8, 2015.

12. Jakobsen E, Green A, Oesterlind K, Rasmussen TR, Iachina M, Palshof T. Nationwide quality improvement in lung cancer care: the Danish Lung Cancer Registry. J Thorac Oncol. 2013;8:1238-1247.
13. Lüchtenborg M, Jakobsen E, Krasnik M, Linklater KM, Mellemgaard A, Møller H. The effect of comorbidity on stage-specific survival in resected non-small cell lung cancer patients. Eur J Cancer. 2012; 48(18):3386-3395.

14. Iachina M, Green A, Jakobsen E. The direct and indirect impact of comorbidity on the survival of patients with non-small cell lung cancer: a combination of survival, staging and resection models with missing measurements in covariates. BMJ Open. 2014;4:e003846.

15. Mellemgaard A, Lüchtenborg M, Lachina M, et al. Role of comorbidity on survival after radio- and chemotherapy for non-surgically treated lung cancer. J Thorac Oncol. 2015;10(2):272-279.

16. Iachina M, Jakobsen E, Møller H, et al. The effect of different comorbidities on survival of non-small cells lung cancer patients. Lung. 2015;193:291-297.

17. Dalton S, Frederiksen B, Jacobsen E, et al. Socioeconomic position, stage of lung cancer and time between referral and diagnosis in Denmark, 2001-2008. Br J Cancer. 2011;105:1045-1048.

18. Kærgaard Starr L, Osler M, Steding-Jessen M, et al. Socioeconomic position and surgery for early-stage non small cell lung cancer: a population-based study in Denmark. Lung Cancer. 2013;79: 262-269.

19. Dalton S, Steding-Jessen M, Jakobsen E, et al. Socioeconomic position and survival after lung cancer - the influence of stage, treatment and comorbidity among Danish lung cancer patients diagnosed 2004-2010. Acta Oncol. 2015;54(5):797-804.
Clinical Epidemiology

\section{Publish your work in this journal}

Clinical Epidemiology is an international, peer-reviewed, open access, online journal focusing on disease and drug epidemiology, identification of risk factors and screening procedures to develop optimal preventative initiatives and programs. Specific topics include: diagnosis, prognosis, treatment, screening, prevention, risk factor modification,

\section{Dovepress}

systematic reviews, risk \& safety of medical interventions, epidemiology \& biostatistical methods, and evaluation of guidelines, translational medicine, health policies \& economic evaluations. The manuscript management system is completely online and includes a very quick and fair peer-review system, which is all easy to use. 